\title{
The relation between type $D$ personality and the clinical condition of patients suffering from psoriasis
}

\author{
Małgorzata A. Basińska, Agnieszka Woźniewicz
}

Department of Psychopathology and Clinical Diagnosis, Institute of Psychology, Kazimierz Wielki University, Bydgoszcz, Poland Head of the Institute: Prof. Janusz Trempała

Postep Derm Alergol 2013; XXX, 6: 381-387

DOI: $10.5114 /$ pdia.2013.39437

\begin{abstract}
Introduction: Type D personality is the last distinguished specific type of personality that is characterised by two dimensions: a tendency for feeling negative emotions - depression, anxiety, anger or hostility, and a tendency for withdrawal from the society. The latest research shows the significant role played by type D personality in the aetiology and course of a variety of diseases.

Aim: The article discusses the problem of the occurrence of type D personality in the group of patients suffering from psoriasis. Diversities in the clinical condition of psoriasis patients due to increasing type $D$ personality traits are specified.

Material and methods: Ninety psoriasis patients and 86 healthy subjects participated in the research. In the research questionnaires, the scale for assessing increasing psoriasis complaints and the DS-14 scale to assess type D personality were applied.

Results: Research results made it possible to corroborate more frequent occurrence of type D personality among psoriasis patients. Moreover, it was found that with increasing negative affectivity - one of type D personality components - complaints increase as far as the clinical condition of psoriasis patients is concerned.

Conclusions: Monitoring of psychological well-being of psoriasis patients, especially within type D personality, seems to be a vital element, irrespective of purely medical treatment.
\end{abstract}

Key words: type D personality, psoriasis, increase in complaints.

\section{Introduction}

Psoriasis is one of autoaggressive diseases, i.e. diseases in the course of which the immune system attacks the cells of the body system. The occurrence of pathological lesions, their persistence and returns are determined by a variety of intrasystemic and exogenous factors, predispositions of the individual to illnesses and non-specific personality traits [1-5].

The skin is an organ that reacts to the psychological well-being; it reflects the physical and mental state [6]. Skin diseases, in the majority of cases, do not pose a direct hazard to health, and that is why problems of individuals with various dermatoses are frequently ignored or reduced to minor problems of a cosmetic nature [7]. In reality, skin lesions are visible to the environment and can strongly affect the patients' psychological well-being
[8]. In patients suffering from psoriasis, psychophysiological disorders occur: there is a correlation between the occurrence or advancement of skin lesions and the psychological well-being of the patient [9].

As far as research on the role of psychological factors in the aetiology and course of diseases is concerned, three factor types can be distinguished: personality, behavioural and social [10]. This article addresses the relationship between type D personality and the clinical condition of psoriasis patients.

The associations between personality and health can be manifested in a variety of ways. Personality can be treated in causal categories as a disease risk factor. Certain biological mechanisms fundamental for personality tend to shape it and simultaneously affect predispositions to fall ill [11].

Address for correspondence: Małgorzata A. Basińska PhD, Prof. UKW, Department of Psychopathology and Clinical Diagnosis, Institute of Psychology, Kazimierz Wielki University, 1 Staffa St, 85-867 Bydgoszcz, Poland, phone: +48 5237084 00, fax: +48 523708402 , e-mail: mbasinska@ukw.edu.pl, malbasinska@wp.pl

Received: 21.01.2013, accepted: 23.06.2013. 
The results of research to date allow us to formulate a claim that personality, expressed in relatively permanent traits, is a kind of a mediator between stress resulting from the environment and the onset, development and course of a somatic disease [12].

The effect of personality on health is a two-way one: direct through physiological mechanisms and indirect through stress experienced as well as ways of coping with it, and also through preferred health behaviours [11]

The research on causality between personality and disease as well as on predispositions to fall ill is significantly restricted, since personality is only one of a plethora of factors determining the individual's health, and conducting research pertaining to all of them is impossible. Most research is correlational research that does not answer the question about the cause and effect. It should be borne in mind that certain personality traits are conducive to falling ill, but also personality may be subject to changes as a result of a disease, especially when the disease is chronic or incurable. The research conducted so far has focused mainly on seeking risk factors and traits conducive to falling ill $[11,13,14]$.

Cognitive reinterpretation is vital for the process of coping with the disease; it may result in the reduction of negative emotions, and the increase in positive emotions; this may contribute to the body system activating its immunological potential and combating the disease $[11,15]$.

The concept of type D personality, also referred to as the distressed personality, was introduced in the research literature by Johan Denolett from the University of Tilburg, the Netherlands, in 1995. The emergence of this new personality type was a consequence of ambiguous research results on the role of other complex behavioural patterns in the development and course of somatic diseases [16].

The type $D$ personality embraces two major dimensions, treated as relatively stable personality traits, namely, negative affectivity and social inhibition. Negative affectivity is concerned with tendencies to experience strong negative emotions such as anxiety, anger, hostility, irritability. Social inhibition is expressed in the tendency to refrain oneself from expressing negative emotions and behaviours concurrent with these emotions. Inhibition occurs mostly in social situations, and the individual is aware of being inhibited. This behaviour results from the fear of being disapproved of and rejected by others. Individuals with type D personality are characterised by the following traits: a tendency to worry and feel stressed, low (or lack of) sense of security, pessimistic outlook on life, feeling unhappy, poor tendency to share emotions with others mainly due to the fear of being disapproved of and rejected, sense of discomfort in the presence of other people, mainly strangers, weak bonds with other people and a tendency to blame oneself. Moreover, the distressed personality is connected with such symptoms of psychological stress as depression, difficulties in utilising social support, feeling bad, low self-esteem, low level of life satisfaction as well as a sense of exhaustion [16, 17].

In type $D$ individuals processes of cognitive assessment and ways of coping with stress are realised in a specific way. This is to be observed in the three components: cognitive, affective and behavioural. Type D individuals perceive the world around in a peculiar manner. Negative affectivity, which seems to be a permanent trait, precedes the process of cognitive assessment and ways of coping, which is conducive to assessing events as threatening and harmful. Negative affection, typical of type $D$, results in the individual perceiving the reality as a threat (cognitive component), which secondarily intensifies negative emotions such as anxiety, fear, anger, hostility, irritability (affective component) and induces assuming a defensive attitude and to cope with these emotions. Type D personality most frequently copes through inhibiting from expressing emotions and behaviours conformant with emotions (behavioural component). As a result, the sense of stress is enhanced and leads to changes in the autonomic nervous and somatic systems that further on result in the development of the disease or deterioration of health $[11,18]$.

Type D personality should not be treated as pathology. It is considered as an extreme verge of dimensions viewed as psychological norms [11, 19]. The first research claiming that type $D$ personality negatively affects health was published in 1995 [17]. This personality type is, most of all, treated as a risk factor for somatic diseases. The research to date has shown that type $D$ individuals are four times more prone to falling ill with coronary heart disease than persons not revealing any traits of type $D$ personality. Moreover, in these patients, mortality resulting from these diseases is higher [17]. Research results demonstrated higher occurrence of type D personality among hypertensive patients in comparison to the general population. The research to date has also shown that type D personality traits affect rehabilitation effects in cardiac patients [19]. What is more, one of traits of type $D$ personality - negative affectivity - is a predictor of such diseases as coronary heart disease, hypertension, cancer, peptic ulcer disease and psoriasis. Social inhibition fulfils a predictive role in such diseases as coronary heart disease, hypertension, cancer and peptic ulcer disease [11]. The probability of a subsequent heart attack in type $D$ individuals with coronary heart disease is $52 \%$, and in persons who do not reveal these personality traits $-12 \%$ [20]. Seventy-three percentage of cases of death for cardiac reasons were found in persons with type $D$ personality [21]. Longitudinal research showed that the mortality rate of patients with type $D$ personality 6 years after the first measurement test was $27 \%$, and in persons that did not have this personality type - 7\% [22]. Pedersen and Denollet repeated the research in 2000; type D person- 
ality appeared to be a predictor of the disease as well as disease-related mortality. Patients with type D personality considered their health and life quality as worse [17].

Psoriasis patients suffer from psychophysiological disorders, which denotes a correlation between the occurrence or advancement of skin lesions and the patient's psychological health. Stress, conflicts experienced and internal tension release adverse physiological changes in the body [9].

Research on the relation between psychological factors and psoriasis was instigated in line with the psychosomatic approach. The focus was laid on psychogenic determinants of psoriasis, and attempts were made to connect the occurrence and subsequent returns of the disease with such psychological variables as conflicts, personality traits, negative events in one's life or stress. Currently, the disease itself is considered as the source of stress and it is beyond any doubt that the relation between stress and psoriasis goes bidirectionally [23]. The research conducted by Ogińska-Bulik and Juczyński [24] demonstrates that the component of type $\mathrm{D}$ personality - negative affectivity - turned out to be a determinant of psoriasis.

\section{Aim}

The article aims at verifying whether psoriasis patients differ from healthy individuals as regards type $D$ personality as well as at determining the correlation between the health of patients and the occurrence of type D personality.

\section{Material and methods}

The following research instruments were applied in the research presented: personal questionnaire, the scale specifying the increase in complaints associated with psoriasis, DS14 personality scale by Ogińska-Bulik, Juczyński and Denollet.

A personal questionnaire is an instrument which was used for gathering information on the psycho-social situation of patients and their health. The following health determinants were considered: duration of the disease in years, disease-related complications and comorbidity.

The increase in complaints was determined by means of a self-assessment scale that evaluates the increase in psoriasis-related complaints and considers such determinants as pain, burning, itching and irritation. Each of the determinants was given points, ranging 1 to 5 , by the researcher where 1 stood for the highest score, and 5 the lowest score for each of those complaints. In general, the highest score for complaints was 4 points, and the lowest 20 points.

The DS-14 personality scale by Ogińska-Bulik, Juczyński and Denollet is a tool for testing adult patients and healthy individuals. It comprises 14 statements, out of which seven measure the tendency to sense negative emotions (negative affectivity - NA), and the remaining seven measure the tendency to inhibit oneself from expressing those emotions and relevant behaviours (social inhibition - SI). Each statement is evaluated on a fivepoint scale, from 0 - false to 4 - true. The scale is applied to measure the increase in traits of type $D$ personality. Results for negative affectivity and social inhibition are calculated separately. A higher score denotes a higher increase in traits comprising a given dimension [25].

Reliability of the scale was evaluated on a group of 1,154 persons (healthy individuals and cardiac patients). The Cronbach's $\alpha$ coefficients amount to: 0.86 for the NA scale and 0.84 for the SI scale. Reliability of the scale was evaluated by the test-retest method after 3 months on a group of 60 healthy individuals and amounted to 0.76 for the NA scale and 0.73 for the SI scale. In the group of 40 cardiac patients it amounted to 0.74 for the NA scale and 0.70 for the SI scale [25].

Accuracy was specified on a group of 1,154 healthy individuals and cardiac patients. Two factors were distinguished by means of factor analysis. The first, referred to as Negative Affectivity, accounted for $40.3 \%$ of result variance, and the other - Social Inhibition - for $12.9 \%$ of result variance. Accuracy of criteria was specified on the basis of correlations with other instruments for measuring dimensions similar to type D. Both dimensions of type $D$ personality show a relation with the intensity of stress experienced, general health measured by the GHQ-28 scale questionnaire, with negative and positive affections and one of the aspects of psychological disposition, namely, affective responsiveness [25].

\section{Research subjects}

The group of patients embraced persons with diagnosed psoriasis who expressed their written consent to take part in the research. At the same time the control group was subject to research; this group included healthy individuals selected in line with the following criteria:

- sex, age, education (patient-adjusted),

- health (these persons did not suffer from somatic diseases or mental disorders),

- informed consent to take part in the research.

After having obtained the consent of the relevant Bioethical Commission and the head of the Clinic, 90 psoriasis patients and 86 healthy individuals were subject to examinations. The group of patients included 46 women and 44 men aged 18-70. The mean age for the entire group of research subjects was 41.58 years (SD = 13.71). In the group of male patients, the mean age was 40.50 years $(S D=14.54$; aged $18-66)$, and in the group of female patients -42.60 years $(S D=12.93$; aged $19-70)$.

In the control group, 44 women and 42 men were examined; the youngest person was 20, and the oldest 70 . The mean age was 42.00 years $(S D=13.79)$. For men the 
Table 1. Disease duration in years and increase in psoriasis-related complaints - mean results for the entire group and according to sex ratio

\begin{tabular}{|c|c|c|c|c|c|c|}
\hline \multirow{2}{*}{$\begin{array}{l}\text { Clinical condition } \\
\text { determinants }\end{array}$} & \multicolumn{2}{|c|}{ Women } & \multicolumn{2}{|c|}{ Men } & \multicolumn{2}{|c|}{ Total } \\
\hline & Mean & $\begin{array}{l}\text { Standard } \\
\text { deviation }\end{array}$ & Mean & $\begin{array}{l}\text { Standard } \\
\text { deviation }\end{array}$ & Mean & $\begin{array}{l}\text { Standard } \\
\text { deviation }\end{array}$ \\
\hline Disease duration & 17.74 & 13.37 & 19.74 & 12.34 & 18.76 & 12.82 \\
\hline Complaints & 12.98 & 3.89 & 13.19 & 4.24 & 13.09 & 4.05 \\
\hline
\end{tabular}

mean was 43.64 (SD = 12.58; aged 20-70), and for women -40.43 (SD = 14.83; aged 20-68). Both groups were comparable in terms of the subjects' age.

In the group of psoriasis patients, the number of persons with vocational and secondary education was the highest, the lowest - with primary education. In the control group, there were more persons with secondary education, with no persons with primary education. As far as marital status is concerned, in both groups married persons were predominant, with the lowest number of widowed or divorced persons. Some subjects did not give any answers pertaining to their marital status.

Considering the state of disease, such aspects as disease duration (in years), complications or the absence of them, comorbidity or increase in such complaints as pain, burning, itching and irritation (Table 1) were taken into account. All the aforementioned parameters were slightly higher in men, yet the difference was not statistically significant (for disease duration $p=0.463$; for complaints $p=0.807$ ).

About $73 \%$ of patients suffered from complications, and in majority of them (89\%) other somatic diseases co-occurred.

\section{Statistical analysis}

The data obtained were subject to quantitative analysis applying such basic descriptive statistics as mean results $(M)$, standard deviation (SD) and median. The normality of result distribution was verified by the Shapiro-Wilk test. In order to verify the significance of differences between groups under research, the $t$-Student test was applied for independent samples ( $t$ ), and in case of a failure to fulfil conditions referring to normal distribution and homogeneity of the variance test, the nonparametric U Mann-Whitney (z) test was applied. Calculations were made with the use of Statistica 9.0 statistical software.

\section{Results}

The occurrence of type D personality was observed in the group of psoriasis patients. However, this result should be considered with care since it is only slightly above the limit for type D. No type D personality was found in the group of healthy individuals (Table 2). Statistically significant differences occurred between the groups of patients and healthy individuals in terms of negative affectivity $(t=4.15, p<0.05)$, whereas for social inhibition the difference was not statistically significant $(t=1.91, p=0.58)$. Psoriasis patients experienced more negative emotions than healthy individuals.

Differences were found in the increase in components of type $D$ personality considering the sex ratio in the groups of patients and healthy individuals. In the group of female patients, a significantly higher increase in negative affectivity and social inhibition was observed. Thus, female psoriasis patients had more negative affection and were more socially inhibited than healthy female individuals (Table 3). Male psoriasis patients differed significantly from healthy male individuals in terms of negative affectivity. They tended more frequently to express negative affection in comparison to healthy male individuals (Table 4).

Mean results for complaints are within the range of moderate forms of psoriasis. Complaints were assessed considering such determinants as pain, burning, itching and irritation (Table 5).

Table 2. Mean results of psoriasis patients and healthy individuals as for type $D$ factors

\begin{tabular}{|c|c|c|c|c|c|c|c|}
\hline Test scales & & $N$ & Mean & $\begin{array}{l}\text { Standard } \\
\text { deviation }\end{array}$ & Median & Minimum & Maximum \\
\hline DS14 Negative affectivity & \multirow{2}{*}{ 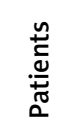 } & 90 & 12.66 & 6.60 & 12.00 & 0.00 & 28.00 \\
\hline DS14 Social inhibition & & 90 & 10.01 & 5.98 & 10.00 & 0.00 & 26.00 \\
\hline DS14 Negative affectivity & \multirow{2}{*}{ 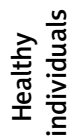 } & 86 & 9.01 & 4.89 & 8.00 & 0.00 & 22.00 \\
\hline DS14 Social inhibition & & 86 & 8.34 & 5.64 & 17.00 & 0.00 & 42.00 \\
\hline
\end{tabular}


Table 3. Significant results in terms of type D personality traits - comparison between female patients and female healthy individuals

\begin{tabular}{|c|c|c|c|c|c|c|}
\hline \multirow[b]{2}{*}{ Test scales } & \multicolumn{2}{|c|}{ Patients } & \multicolumn{2}{|c|}{ Healthy individuals } & \multirow[b]{2}{*}{ Value of $t$} & \multirow[b]{2}{*}{ Value of $p$} \\
\hline & Mean & $\begin{array}{l}\text { Standard } \\
\text { deviation }\end{array}$ & Mean & $\begin{array}{l}\text { Standard } \\
\text { deviation }\end{array}$ & & \\
\hline DS14 Negative affectivity & 14.52 & 6.94 & 10.05 & 5.02 & 3.467 & 0.001 \\
\hline DS14 Social inhibition & 10.77 & 5.37 & 8.09 & 5.55 & 2.302 & 0.024 \\
\hline
\end{tabular}

Table 4. Significant results in terms of type D personality traits - comparison between male patients and male healthy individuals

\begin{tabular}{|c|c|c|c|c|c|c|}
\hline \multirow[b]{2}{*}{ Test scales } & \multicolumn{2}{|c|}{ Patients } & \multicolumn{2}{|c|}{ Healthy individuals } & \multirow[b]{2}{*}{ Value of $t$} & \multirow[b]{2}{*}{ Value of $p$} \\
\hline & Mean & $\begin{array}{l}\text { Standard } \\
\text { deviation }\end{array}$ & Mean & $\begin{array}{l}\text { Standard } \\
\text { deviation }\end{array}$ & & \\
\hline DS14 Negative affectivity & 9.28 & 6.48 & 8.60 & 5.78 & 2.635 & 0.010 \\
\hline
\end{tabular}

Table 5. Mean results for psoriasis-related complaints in the entire group as well as for women and men

\begin{tabular}{lccccccc}
\hline \multirow{2}{*}{ Complaints } & \multicolumn{2}{c}{ Women } & \multicolumn{2}{c}{ Men } & \multicolumn{2}{c}{ Total } \\
\cline { 2 - 7 } & Mean & $\begin{array}{c}\text { Standard } \\
\text { deviation }\end{array}$ & Mean & $\begin{array}{c}\text { Standard } \\
\text { deviation }\end{array}$ & Mean & $\begin{array}{c}\text { Standard } \\
\text { deviation }\end{array}$ \\
\hline Pain & 14.74 & 4.72 & 14.87 & 5.19 & 14.81 & 4.94 \\
\hline Burning & 14.39 & 4.83 & 14.64 & 5.27 & 14.52 & 5.03 \\
\hline Itching & 10.93 & 4.47 & 11.38 & 4.99 & 11.16 & 4.72 \\
\hline Irritation & 11.86 & 4.48 & 11.87 & 5.08 & 11.86 & 4.77 \\
\hline Complaints - in total & 12.98 & 3.89 & 13.19 & 4.24 & 13.09 & 4.05 \\
\hline
\end{tabular}

Table 6. Statistically significant differences in the increase in type D personality traits as a result of increasing complaints in the group of psoriasis patients

\begin{tabular}{|c|c|c|c|c|c|c|}
\hline \multirow{2}{*}{ Test scales } & \multicolumn{2}{|c|}{ Higher increase in complaints } & \multicolumn{2}{|c|}{ Lower increase in complaints } & \multirow{2}{*}{$\begin{array}{c}\text { Value } \\
\text { of } t\end{array}$} & \multirow{2}{*}{$\begin{array}{c}\text { Value } \\
\text { of } p\end{array}$} \\
\hline & Mean & Standard deviation & Mean & Standard deviation & & \\
\hline DS14 Negative affectivity & 10.864 & 6.414 & 14.455 & 6.356 & -2.638 & 0.010 \\
\hline
\end{tabular}

Table 7. Statistically significant differences in type D personality traits between men and women in the group of psoriasis patients

\begin{tabular}{|c|c|c|c|c|c|c|}
\hline \multirow{2}{*}{ Test scales } & \multicolumn{2}{|r|}{ Women } & \multicolumn{2}{|r|}{ Men } & \multirow{2}{*}{$\begin{array}{c}\text { Value } \\
\text { of } t\end{array}$} & \multirow{2}{*}{$\begin{array}{c}\text { Value } \\
\text { of } p\end{array}$} \\
\hline & Mean & Standard deviation & Mean & Standard deviation & & \\
\hline DS14 Negative affectivity & 14.523 & 6.940 & 10.870 & 5.780 & 2.718 & 0.008 \\
\hline
\end{tabular}

In relation to the clinical condition of the subjects, differences were observed in the increase in type D personality traits. The influence of the following health determinants was analysed: disease duration, increase in complaints, occurrence of complications and comorbidity. For the disease duration and complaints, two groups were distinguished, and the results obtained were divided by means of the median test. For complications and comorbidity, the occurrence or the absence of those determinants were taken into consideration.

With increasing complaints, patients expressed higher levels of negative affectivity (Table 6).

Psoriasis patients did not differ significantly in terms of the increase in type $D$ personality traits when the following determinants were considered: disease duration, occurrence of complications and comorbidity. 
One statistically significant difference was found in the increase in one type $D$ personality trait - negative affectivity - in terms of a demographic variable: sex. Women had higher levels of negative affectivity than men (Table 7). The patients under research did not differ significantly in terms of the increase in type D personality traits according to age.

\section{Discussion}

The results obtained corroborate prior findings on the occurrence of type $D$ personality in patients suffering from chronic somatic diseases [24]. In the research presented female psoriasis patients expressed higher levels of negative affectivity in comparison to men. The research conducted by Boguszyńska-Górnicka et al. [26] demonstrates that female psoriasis patients show specific emotional disorders, a higher level of anxiety, tendencies to conversion reactions, substantial concentration on health-related problems as well as they are intensely affected by internal emotional conflicts. Moreover, in the group of female psoriasis patients, more difficulties with accepting the disease were observed when the patients were acting in haste [27], which is usually accompanied by the increase in negative affection [28]. Psoriasis patients differ among one another (in sex ratio) in terms of stress management strategies. Women significantly less frequently than men seemed to use the sense of humour, and more frequently emotional release [29]. It should be noted however that female psoriasis patients, despite having experienced more negative affection than healthy female individuals, were able to use positive emotions in thinking and acting in a more successful way in comparison to male psoriasis patients [30]. It seems that sex in the statistical model is an important factor determining the course of the disease in the group of psoriasis patients [31].

In psoriasis patients a correlation has been observed between the occurrence or advancement of skin lesions and the psychological well-being of the patient [9]. Exacerbation of psoriasis is related with the psychological well-being of patients because returns are frequently associated with exposure to stress [32]. Psoriasis-related stress on a daily basis is reflected in the form of physical complaints, negative emotions, unpleasant experiences in social situations, problems at work, the sense of personal debasement, problems in interpersonal contacts and in sexual relations [23]. The research conducted corroborated the relation between negative affectivity and the increase in complaints in psoriasis patients. This result may be compared with prior research saying that psoriasis is, to a substantial extent, modified by psychological factors [33]. Other research results allowed us to claim that a relation exists between the course of disease and the mood. Younger persons, women, in whom the disease has been going on for a shorter period of time, with more intensive complaints and more body surface covered with lesions, had more negative moods than elderly persons, men, in whom the disease has lasted for a long time, with less intensive complaints and less body surface covered with lesions [34]. It should be borne in mind that the role of the so-called personal resources, i.e. those psychological traits that help in coping with a difficult situation might be limited, especially when symptoms of the disease are prominent [30]. As research results demonstrate, the clinical condition is not always related with the psychological well-being of patients. For instance, the thyroid hormone concentrations did not differentiate between patients with autoaggressive thyroid diseases in terms of the illness acceptance [13]. The clinical condition reflected in the increase in symptoms measured by means of the PASI scale did not differentiate either between ways of coping applied or acceptance of the illness by psoriasis patients [29].

The results obtained reveal relations between clinical conditions of psoriasis patients and their emotional functioning. While preparing and planning treatment, one should take into consideration the fact of occurrence of type D personality in this group of patients. Psychotherapy is a beneficial form of supporting basic treatment as it decreases the frequency and intensity of returns [35].

\section{References}

1. Opalińska M, Prystupa K, Stąpór W. Practical dermatology [Polish]. Wydawnictwo Lekarskie PZWL, Warsaw 1997.

2. Gliński W, Wolska H. Ways of proceeding in psoriasis [Polish]. Konsensus PTD. Przegl Dermatol 2000; 87: 465-71.

3. Raychaudhuri SP, Gross J. Psoriasis risk factors: role of lifestyle practices. Cutis 2000; 66: 348-52.

4. Wielowieyska-Szybińska D, Wojas-Pelc A. Psoriasis: course of disease and treatment. Postep Derm Alergol 2012; 19 : $118-22$.

5. Rasmy H, Mikhael N, Ismail S. Interleukin-18 expression and the response to treatment in patients with psoriasis. Arch Med Sci 2011; 7: 713-9.

6. Januszewska E. Psychosomatic aspects of skin diseases (neurodermitis) [Polish]. In: Selected issues in clinical psychology and personality. Szewczyk L, Kulik A (eds.). TN KUL, Lublin 2001; 97-117.

7. Choi J, Koo J. Quality of life issues in psoriasis. J Am Acad Dermatol 2003; 49: 57-61.

8. Szepietowski J, Pacan P. Dermatoses requiring psychiatric and psychological help [Polish]. Adv Clin Exp Med 2001; 10 (Suppl. 1): 25-8.

9. Pietrzak A, Janowski A, Lechowska-Mazur I, Krasowska D. Psoriasis as a chronic skin disease in psychological context [Polish]. Nowa Medycyna 2006; 1: 14-9.

10. Dolińska-Zygmunt G. Psychological determinants of vulnerability to diseases [Polish]. In: Foundations of health psychology. Dolińska-Zygmunt G (ed.). Wydawnictwo Uniwersytetu Wrocławskiego, Wrocław 2001; 169-89.

11. Ogińska-Bulik N, Juczyński Z. Personality, stress and health [Polish]. Difin, Warsaw 2008.

12. Van Heck GL. Personality and physical health: toward an ecological approach to health-related personality research. Eur J Personality 1997; 11: 415-43. 
13. Basińska MA. Psychological functioning of patients in selected endocrinological diseases. Somatic and personality determinants [Polish]. Wydawnictwo Uniwersytetu Kazimierza Wielkiego, Bydgoszcz 2009.

14. Zatoński WA, Mańczuk M; Kielce PONS team. POlish-Norwegian Study (PONS): research on chronic non-communicable diseases in European high risk countries - study design. Ann Agric Environ Med 2011; 18: 203-6.

15. Lazarus RS, Folkman S. Stress, appraisal and coping [Polish]. Springer-Verlag, New York 1986.

16. Ogińska-Bulik N. Osobowość typu D. Type D personality. Theory and research [Polish]. Wydawnictwo Wyższej Szkoły Humanistyczno-Ekonomicznej w Łodzi, Łódź 2009.

17. Pedersen SS, Denollet JKL. Type D personality, cardiac events, and impaired quality of life: a review. Eur J Cardiov Prev R 2003; 10: 241-8.

18. Ogińska-Bulik N, Juczyński Z. Distressed personality (Type D) and the risk of occurrence of cardiac diseases [Polish]. In: Development, health, disease. Current problems in psychosomatics. Kosińska-Dec K, Szewczyk L (eds.). Wydawnictwo BEL Studio, Warsaw 2004; 5-17.

19. Ogińska-Bulik N. Work-related stress in social services. Sources - consequences - prevention [Polish]. Difin, Warsaw 2006

20. type-D scale-16. Ann Beh Med 1998; 20: 209-15.

21. Denollet J, Sys SU, Stroobant N, et al. Personality as independent predictor of long-term mortality in patients with coronary heart disease. Lancet 1996; 347: 417-21.

22. Denollet J, Vaes J, Brutsaert D. Inadequate response to treatment in coronary heart disease: adverse effects of type $D$ personality and younger age on 5-year prognosis and quality of life. Circulation 2000; 102: 630-5.

23. Janowski K. Personal determinants of coping with stress in psoriasis [Polish]. Wydawnictwo Polihymnia, Lublin 2006.

24. Ogińska-Bulik N, Juczyński Z. Personality traits conducive to somatic diseases - the role of Type D [Polish]. Psychoonkologia 2008; 12: 7-13.

25. Juczyński Z, Ogińska-Bulik N. Tools for stress measurement and coping [Polish]. Pracownia Testów Psychologicznych, Warsaw 2009.

26. Boguszyńska-Górnicka H, Górnicki A, Borkowska A, et al. Personality profiles of female psoriasis patients [Polish]. Przegl Dermatol 1997; 84: 433-9.

27. Basińska MA, Drozdowska M. Type A behavior in individuals with psoriasis as a determinant of acceptance of the illness. Postep Derm Alergol 2012; 29: 432-9.

28. Bętkowska-Korpała B. The role of Type A behaviour pattern in the secondary prevention of coronary heart disease [Polish]. In: Coronary heart disease. Wrześniewski K, Włodarczyk D (eds.). GWP, Gdańsk 2004, 175-98.

29. Basińska MA, Kasprzak A. Relations between ways of coping with stress and disease acceptance in the group of psoriasis patients. Przegl Dermatol 2012; 99: 692-700.

30. Basińska MA, Woźniewicz A. Emotional intelligence of psoriasis patients as a determinant of disease acceptance [Polish]. Przegl Dermatol 2012; 99: 202-9.

31. Boers M. Does sex of rheumatoid arthritis patients matter? Lancet 1998; 352: 419-20.

32. Barańska-Rybak W, Nowicki R, Jakuszkowiak K, Cubała WJ. Psychodermatology - new branch of medicine [Polish]. Przew Lek 2005; 1: 50-5.

33. Rymaszewska J, Dudek D. Psychological disorders in somatic diseases. Practical diagnostic and treatment tips [Polish]. Via Medica, Gdańsk 2009.
34. Basińska MA, Szymańska L. Relationship of mood with characteristics of the disease among a group of psoriasis patients [Polish]. Przegl Dermatol 2013; 100: 146-53.

35. Nockowski P, Baran W, Szepietowski J. Psoriasis [Polish]. In: Treatment of skin and sexually transmitted diseases. Szepietowski J, Reich A (eds.). Wydawnictwo Lekarskie PZWL, Warsaw 2008; 224-43. 